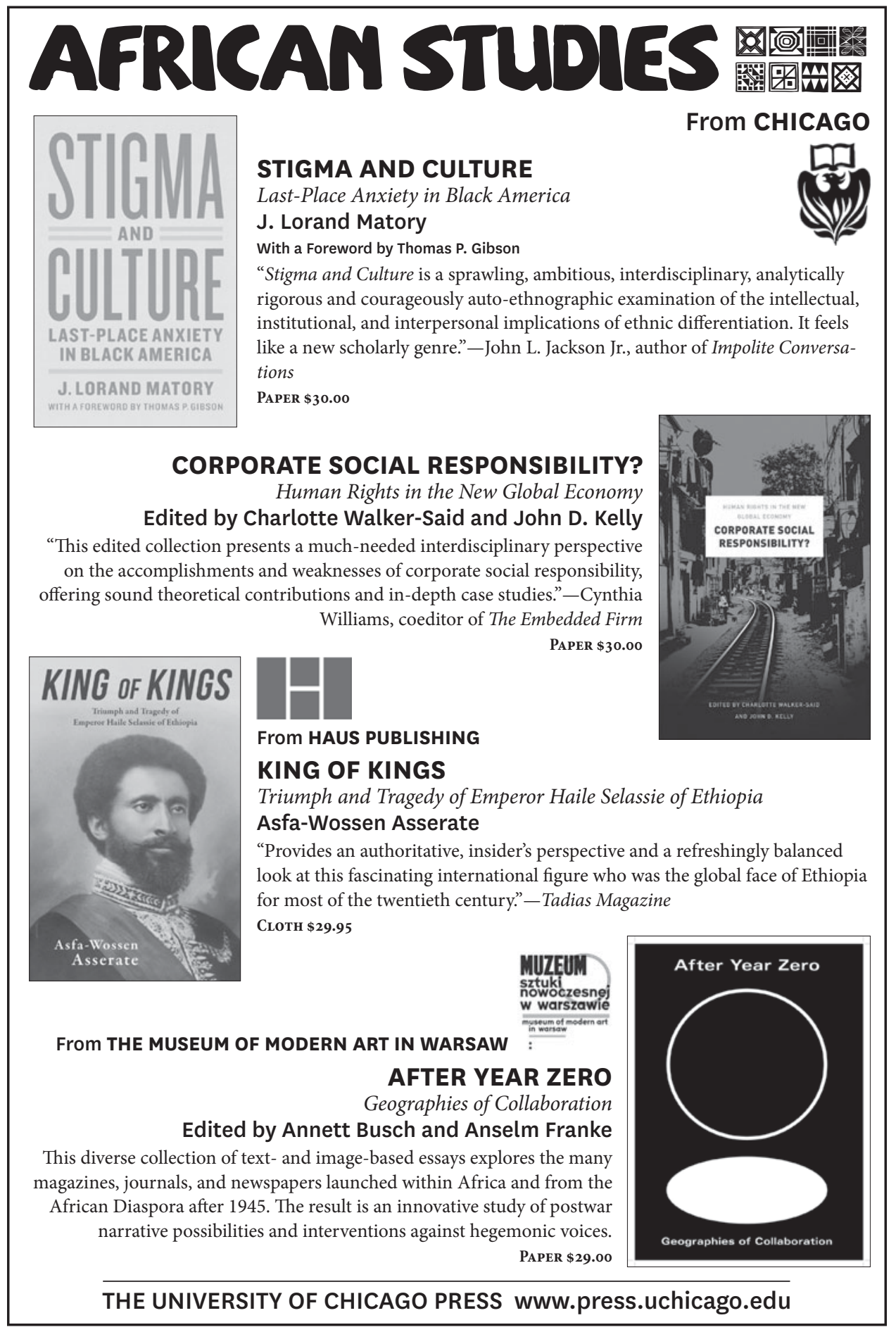




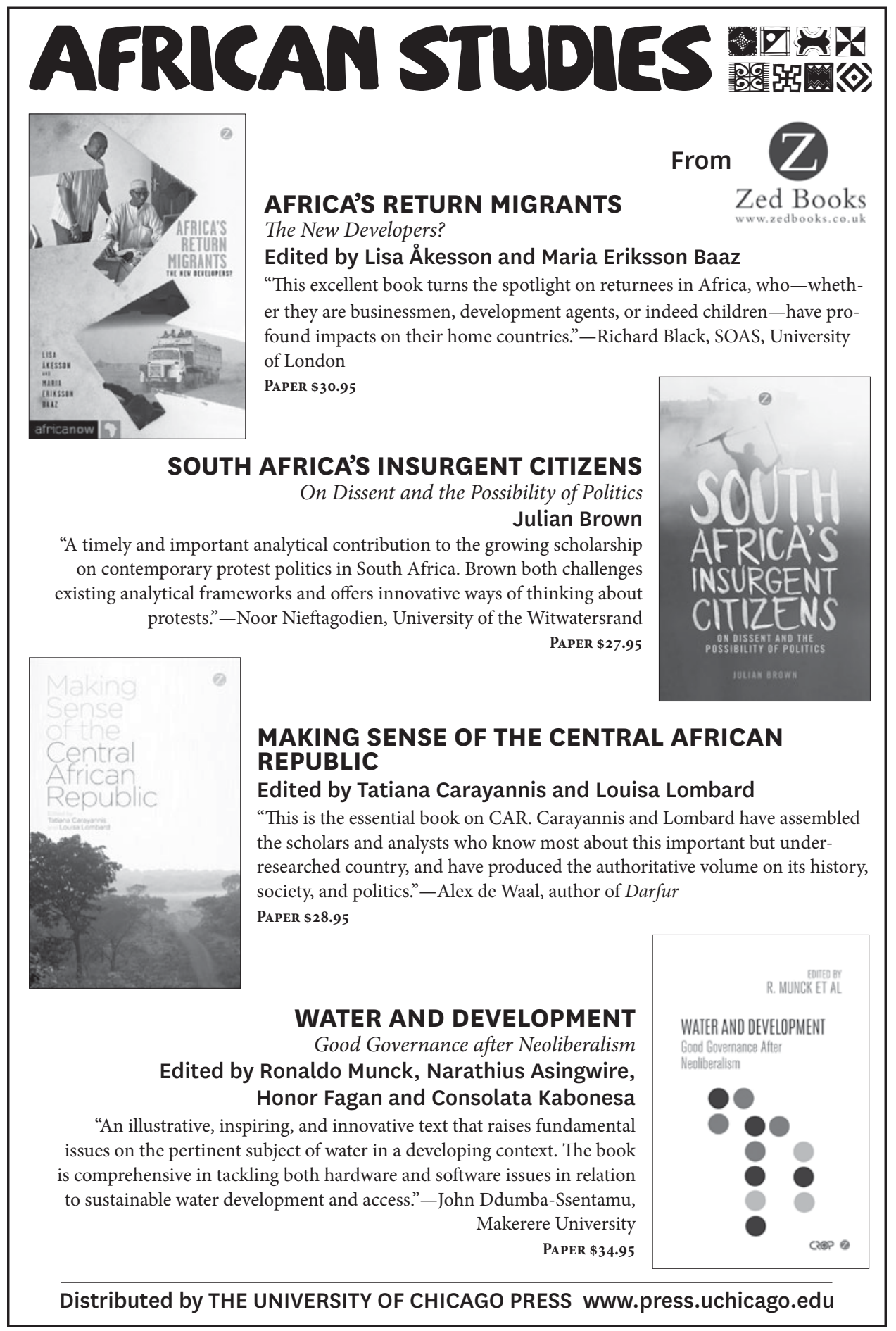




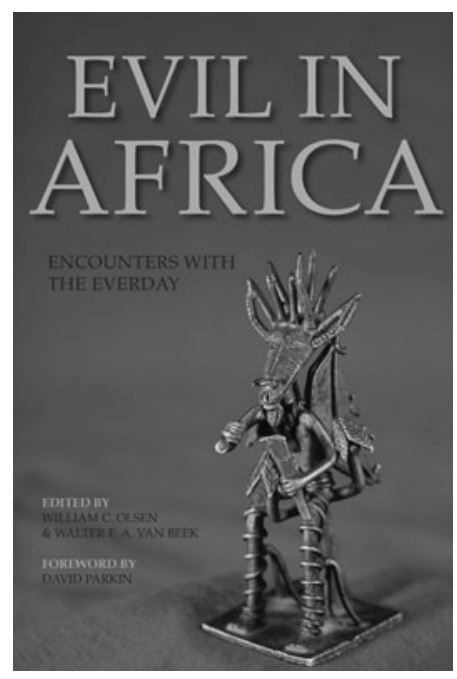

\section{Evil in Africa}

Edited by William C. Olsen and Walter E. A. van Beek

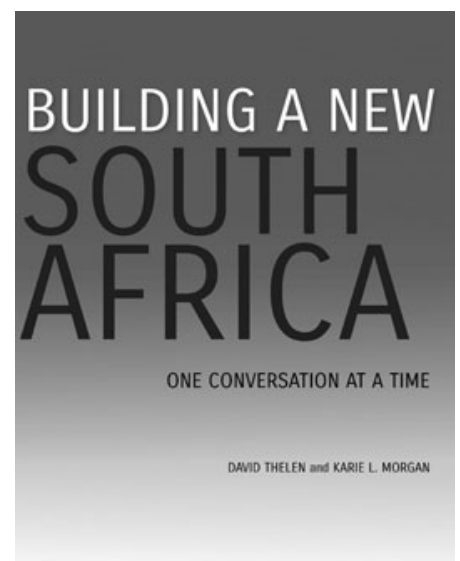

\section{Building a New South Africa}

David Thelen and Karie L. Morgan

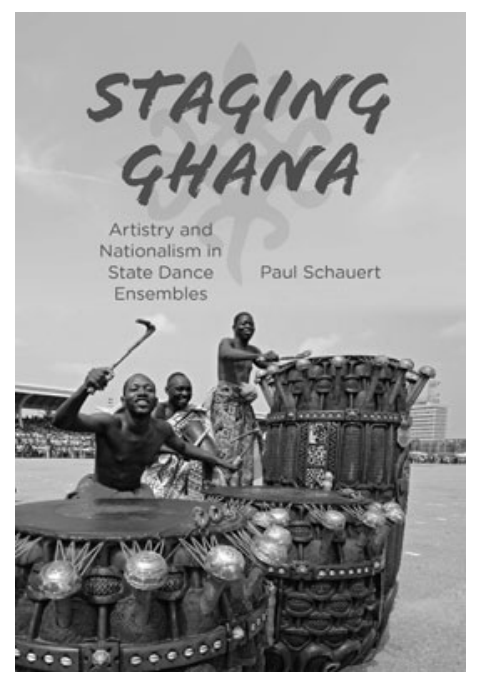

\section{Staging Ghana}

Paul Schauert

\begin{tabular}{l} 
African Appropriations \\
Cultural Difference, Mimesis, and Media \\
Matthias Krings \\
Africa's Past, Our Future \\
Kathleen R. Smythe \\
Rethinking African Cultural Production \\
Edited by Frieda Ekotto and Kenneth W. Harrow \\
Queen of Flowers and Pearls \\
Gabriella Ghermandi \\
Translated by Giovanna Bellesia-Contuzzi and \\
Victoria Offredi Poletto \\
West Africa's Women of God \\
Alinesitoué and the Diola Prophetic Tradition \\
Robert M. Baum \\
African Music, Power, and Being in Colonial \\
Zimbabwe \\
Mhoze Chikowero \\
\hline
\end{tabular}




\section{COLUMBIA UNIVERSITY PRESS}

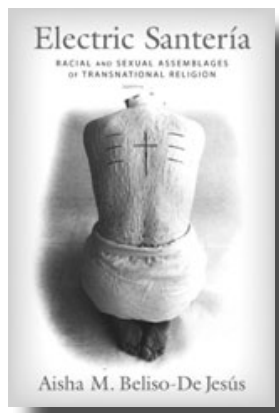

\section{Electric Santería}

Racial and Sexual

Assemblages of

Transnational Religion

Aisha M. Beliso-De Jesús

“A new 'classic' for religious studies and for African diaspora studies."

_-Inderpal Grewal, Yale University

"Ethnographically rich and theoretically audacious, Beliso-De Jesús's Electric Santería breathes fresh air into the scholarship on Afro-Cuban ritual praxis."

-Stephan Palmié, author of The Cooking of History: How Not to Study AfroCuban Religion

978-0-231-17317-9 PB \$30.00/£20.50 978-0-231-53991-3 EB \$29.99/£20.00 Gender, Theory, and Religion

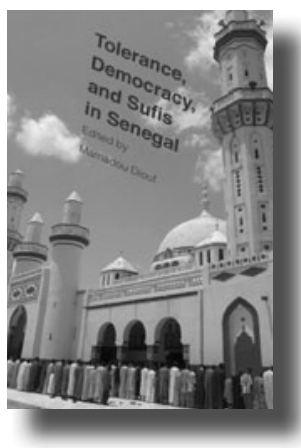

Tolerance, Democracy, and Sufis in Senegal

Edited by Mamadou Diouf

“A very original project that sheds light on the relations between Sufism and democracy in Senegal, West Africa, and globally by combining successful, high-quality articles from history, anthropology, sociology, political science, and religious studies."

- Mohamed Mbodj, coauthor of Senegal:

A Country and Its People

978-0-231-16263-O PB \$32.00/£22.00 978-0-231-53089-7 EB \$31.99/£22.00 Religion, Culture, and Public Life

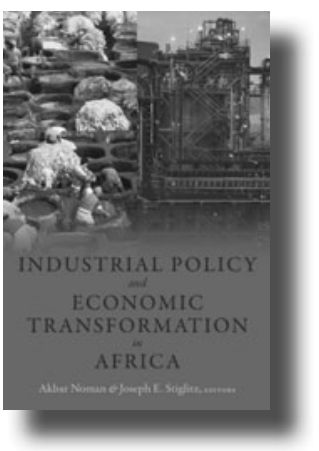

Industrial Policy and Economic Transformation in Africa Edited by Akbar Noman and Joseph E. Stiglitz

"A refreshing and timely intervention in policy debates on the industrialization of African countries. The book is outstanding and should be read not only by those interested in Africa's industrialization but also by readers from other parts of the world who have sought to bring industrial policy back into their own development thinking and endeavors."

-Thandika Mkandawire, London School of Economics

978-0-231-17518-0 CL \$60.00/£41.50 978-0-231-54077-3 EB \$59.99/£41.50 Initiative for Policy Dialogue 


\section{Individual membership}

Membership in the African Studies Association membership is open to scholars, students, and professionals from around the world who have an interest in Africa.

ASA members enjoy many benefits, including:

- A subscription to African Studies Review, a multi-disciplinary scholarly journal, which publishes original research and analyses of Africa and book reviews, as well as a digital subscription to History in Africa*, an annual journal that features textual analysis and criticism, historiographical essays, bibliographical essays, archival reports and articles on the role of theory and non-historical data in historical investigation

- A discounted registration fee to attend the Annual Meeting

- A listing in the ASA Online Membership Directory with an advanced search feature to easily locate ASA colleagues and individuals

- An opportunity to vote to elect officers and members of the Board of Directors

- An opportunity to serve on ASA Committees

- The ability to nominate individuals for the Distinguished Africanist Award

*Print copies of History in Africa are available to members for purchase at the additional price indicated below.

Membership can be purchased securely online at http://journals.cambridge.org/ ASAMBR, or by contacting the member services team at Cambridge University Press. Email: USmemberservices@cambridge.org; Phone (845) 353 7500; Fax (845) 3534141

Membership in the ASA is on a calendar year basis.

Membership (Income equivalent to $\$ 50,000$ and above)

$\$ 180.00$ or $£ 111$ or $€ 137$

Membership (Income equivalent to $\$ 50,000$ and above) + print subscription to HIA $\$ 230.00$ or $\mathrm{f} 143$ or $€ 175$

Membership (Income equivalent to $\$ 49,999$ and below)

$\$ 115.00$ or $€ 71$ or $€ 87$

Membership (Income equivalent to $\$ 49,999$ and below) + print subscription to HIA

$\$ 165.00$ or $\mathrm{f} 102$ or $€ 125$

Retiree Membership

$\$ 100.00$ or $£ 62$ or $€ 76$

Retiree Membership + print subscription to HIA

$\$ 150.00$ or $£ 93$ or $€ 114$

Student Membership (please send a copy of a valid ID)

$\$ 70.00$ or $£ 43$ or $€ 53$

Student membership + print subscription to HIA (please send a copy of a valid ID)

$\$ 120.00$ or $€ 74$ or $€ 91$ 
Cambridge Journals Online

For further information about the journal, please go to the publisher's journal Web site at journals.cambridge.org/ASR 